\title{
Los Estados de Artois y las Concesiones Fiscales a la Monarquía: Las ayudas y los subsidios a comienzos del siglo XVII (1600-1630)
}

\author{
Juan M. Carretero Zamora*
}

\section{LA “COMPOSITION D'ARTOIS". AYUDAS Y SUBSIDIOS DE LOS ESTADOS DE ARTOIS}

Aunque integradas políticamente en los Estados Generales o asamblea representativa de los Países Bajos, cada provincia mantuvo intactas sus competencias fiscales a través de su asamblea particular o Estados Provinciales ${ }^{1}$. Éstos, en dicho ámbito fiscal, poseían una completa autonomía tanto en la negociación de las condiciones de los subsidios demandados desde Bruselas, como en el establecimiento de los medios de repartimiento, recepción y características de los tributos. De hecho, las Cámaras de Cuentas de los Países Bajos - singularmente la de Lille- solian llevar la contabilidad específica de las ayudas concedidas por cada asamblea o Estados Provinciales, haciendo constar siempre el tipo y rendimiento fiscal de los impuestos establecidos para el pago de los subsidios concedidos por los diversos parlamentos. De esta forma actuaron los Estados de Hainaut ${ }^{2}$, de Tournaisis ${ }^{3}$, de Flandes ${ }^{4}$, de Douai, Lille y Orchies ${ }^{5}$ y de Artois.

Universidad Complutense.

Entre otros, pueden consultarse los estudios de J. GILISSEN, Le régime représentatif avant 1790 en Belgique, Bruselas, 1952. A. Stegmann (ed.), Pouvoir et institutions en Europe au XVléme. siècle, Paris, 1987. W. Blockmans, L'histoire parlementaire dans le Pays-Bas et la Belgique, XIle.XVIle. siècles, en Las Cortes de Castilla y León, 1188-1988, Valladolid, 1990.

2 Bibliothèque Nationale de Paris, manuscrits, Colbert, Flandre, 134, Compte rendu des aides et subsides accordés par les Etats de Hainaut.

3 Ibidem, 172, Compte des aides et subsides au roi d'Espagne par les Etats de Tournaisis.

Ibidem, 74, Recueil des aydes ordinaires et subsides extraordinaires de Flandre accordés aux princes souverains du pays. Extrait des registres des receptes et depenses desdits aydes et subsides qui sont en la chambre des comptes du roy à Lille.

5 Las cuentas de las aportaciones de los Estados para el periodo 1647-1650 en Ibidem, 150, Compte des aides accordées à larchiduc Albert par les Ėtats de Douai, Lille et Orchies. Sobre los impuestos creados para el pago de las ayudas, Ibidem, manuscritos 142 y 145-151, Compte des impôts de Lille levés par ordre des États de Douai, Lille et Orchies 
En el caso de Artois, las aportaciones fiscales de sus Estados Provinciales venían condicionadas teóricamente por acuerdos históricos antiguos suscritos entre el parlamento y el soberano. A partir de esta tradición (que hay que tener más por teórica que práctica), las autoridades de la provincia, tanto en la época de los Habsburgo españoles como desde su inclusión en el reino de Francia, solian recordar que "L'Artois est un pays gouverné par ses Etats", siempre con el objetivo de hacer patente la supremacia de la provincia sobre las decisiones o pretensiones - casi siempre en materia hacendística- de los gobiernos de Bruselas o París ${ }^{6}$.

En la base de este debate sobre las aportaciones financieras de los Estados Provinciales de Artois se encontraba la denominada "composition d'Artois". Se trataba de una fórmula fiscal de origen borgoñon por el que la provincia, siempre a través de su asamblea representativa, negociaba la concesión a la monarquía de una determinada cantidad o ayuda; a cambio, ésta mantenía incólumes ciertos privilegios tradicionales de la provincia: libertad de comercio, franqueza general de impuestos directos e indirectos, mantenimiento de exenciones particulares, etc. ${ }^{7}$

En este contexto de pacto fiscal caben situarse las concesiones propias de los Estados de Artois, donde, como veremos a lo largo de este estudio, se solía recordar a la monarquía que cada prestación fiscal debería conllevar la salvaguarda de ciertos privilegios vinculados originariamente a la "Composition", singularmente, en la coyuntura de principios del siglo XVII, en el terreno de las franquicias comerciales y en la exención de alojamientos y mantenimientos de tropas. Técnicamente los Estados de Artois concedieron dos tipos de prestaciones fiscales: las ayudas (aides) y los subsidios (subsides). La diferencia entre ambas venía marcada porque las ayudas se vincularon a las concesiones ordinarias, en tanto los segundos siempre tuvieron un carácter extraordinario y excepcional en función de una coyuntura específica e irrepetible. Prueba de esa excepcionalidad de los subsidios es que éstos tuvieron siempre una tramitación parlamentaria

Sobre este asunto la documentación es abundante. Valga como ejemplo las frecuentes protestas de Artois contra las autoridades de la hacienda francesa desde el momento de la conquista de la provincia, luego reiteradas durante el siglo xvm. En este sentido, Archives Nationales de France, $\mathrm{H}$, liasse 55, Memoire pour les États d'Artois contre les fermiers genéraux.

Ibidem. "L'Artois est un pays gouverné par ses Etats, où les loix des fermes générales ont toujours été inconnues, où tout comerce est libre, où nulle imposition n'a lieu, moyennant une somme fixe à laquelle le pays a toujours été, pour aussi dire, abonné avec son souverain. Cet abonnement s'appelloit anciennement la composition d'Artois. ...par les traités de Madrid, de Cambray et de Crespy, le roy François I, ayant cédé à l'empereur Charles Quint la souveraineté de l'Artois, lui céda en même temps l'ayde ordinaire connue sous le nom de composition». 
diferenciada de las ayudas ordinarias, y unas condiciones de recaudación, plazo de percepción y fuentes de financiación independientes de las concesiones ordinarias. Esta terminología fiscal viene a confirmar, una vez más, la creciente independencia de las prácticas institucionales de los Países Bajos respecto la pretendida identidad con la experiencia administrativa francesa. Esto es, los términos aides y subsides no tuvieron correspondencia con la terminologia fiscal de las asambleas representativas francesas, e incluso con algunas de origen también borgoñón (caso de los Estados Generales del Franco Condado), donde siempre prevaleció el término de don gratuit, tanto para las fórmulas fiscales ordinarias como extraordinarias.

\section{NEGOCIACIÓN Y CONDICIONES DE LAS AYUDAS Y SUBSIDIOS}

Como en el resto de las asambleas representativas de la monarquía de los Habsburgo, la capacidad de convocatoria de los Estados de la provincia de Artois correspondía en exclusiva a la Corona a través del gobernador general de los Países Bajos. Durante este período inicial del siglo xvII las cartas de convocatoria iban firmadas por los archiduques Alberto $e$ Isabel (señores de los Países Bajos desde 1598 hasta 1633), que requerian a los Estados (casi siempre reunidos en la ciudad de Arrás) por motivos fiscales, esto es, para que concediesen las ayudas solicitadas ${ }^{8}$. Reunidos los diputados, los Estados solian iniciarse con la petición oficial de la ayuda demandada por la monarquía, que realizaba el gobernadorpresidente de la provincia en su nombre.

Éste exponía las razones de la petición (casi siempre necesidades surgidas en la financiación del ejército) y proponía la cantidad global de la ayuda o subsidio y los plazos para la percepción de los mismos, aludiéndose siempre a la expiración de la ayuda anterior. Por lo común, los archiduques concluian la petición prometiendo a los Estados que las cantidades obtenidas serian utilizadas para el pago "puntual» del ejército (una clara alusión a las secuelas -frecuentemente denunciadas por los diputados de los Estados Generales de los Países Bajos ${ }^{9}$ - de los desmanes

En ocasiones la petición de convocatoria de los Estados de Artois la realizaba el presidente de la provincia, caso, por ejemplo, de la convocatoria de 13 de noviembre de 1602.

Una visión de conjunto, entre otras, en G. PAHKFR, El ejército de Flandes y el Camino Español, 1567-1659. Madrid. 1991, págs. 231-254. Sobre la actitud de los Estados Generales de los Países Bajos. L. GaChard, Actes des États Généraux de 1600. Bruselas, 1848 
producidos por el impago a las tropas ${ }^{10}$ ). Durante el periodo $1600-1630$ las causas oficiales fueron las siguientes:

\begin{tabular}{|c|c|}
\hline AÑO & CAUSA OFICIAL DE LA DEMANDA \\
\hline 1600 & $\begin{array}{l}\text { Mantenimiento de } 1.000 \text { hombres de infantería y } 3 \text { compañías } \\
\text { de caballería. }\end{array}$ \\
\hline 1601 & Campaña de Ostende. \\
\hline 1602 & $\begin{array}{l}\text { Gastos provocados por "cette longue et funeste guerre intes- } \\
\text { tine causée par ceux que oublians leur devoir". }\end{array}$ \\
\hline 1603 & Guerra contra los rebeldes de Holanda y Zelanda. \\
\hline 1604 & Invasión holandesa de los Paises Bajos. \\
\hline 1605 & Liquidación de préstamos contraídos con particulares. \\
\hline 1606 & Continuación de la guerra contra los rebeldes. \\
\hline 1607 & Mantenimiento del ejército sobre los rebeldes. \\
\hline 1608 & Mantenimiento de diversas compañias de caballería. \\
\hline 1609 & Gastos por licenciamiento de una parte del ejército. \\
\hline 1610 & $\begin{array}{l}\text { Ayuda para el socorro de los gastos de la casa de los archi- } \\
\text { duques. Gastos de levas y seguridad de la provincia. }\end{array}$ \\
\hline 1611 & Prórroga y ampliación de la ayuda ordinaria anterior. \\
\hline 1612 a 1617 & Prórroga de las ayudas ordinarias. \\
\hline 1625 & Pago para el mantenimiento de un tercio de 600 hombres. \\
\hline 1626 & Mantenimiento por 3 meses de tropas destinadas en Artois. \\
\hline 1627 y 1628 & Gastos por mantenimiento de tropas. \\
\hline 1629 & Ayuda para el socorro de la ciudad de Bois-le-Duc. \\
\hline 1630 & Mantenimiento de tropas. \\
\hline
\end{tabular}

Tras la lectura de la posición oficial de los archiduques, los diputados deliberaban sobre la propuesta recibida (generalmente el debate se celebraba en una sala de la abadía de Saint Vaast de Arrás) y realizaban una contraoferta, generalmente a la baja, mediante una serie de condiciones

La promesa de los archiduques a los Estados Provinciales de Artois en Bibliothèque Nationale de Paris (en adelante. BNP), manuscrits, Colbert, Flandre, 87, Recueil des aydes ordinaires et subsides extraordinaires d'Artois, accordez aux princes souverains du pays, pendant differentes an. nées depuis lan 1600 jusques en 1657 (en adelante, Recueil des aides...). Textualmente se decía "Sus altezas tienen la intención de mantener en campaña cuatro regimientos valones, y pagarlos puntualmente cada mes como al resto de la gente de guerra" (Lettres d'acceptation des gens de finances sous le nom des archiducs Albert et isabelle, Gante, 31 de julio de 1600). Quizá fuera una reacción a los motines de Calais de 1597-1598.

16 En este sentido, como un ejemplo más, una de las condiciones impuestas por los Estados Provinciales de Flandes a la archiduquesa Isabel en la concesión de la ayuda de 1 de noviembre de 1630 : «... a condition que l'infante Isabelle, gouvernante des Pays Bas, fera effectuer ses promesses tant de fois reiterées de faire payer les soldats et remedier à tous les desordres insuportables qu'ils commettent dans la dite province". 
en la percepción y gasto, así como el mantenimiento de privilegios comerciales o anulación de ciertos decretos lesivos para la marcha económica de la provincia.

Las fricciones entre los diputados y los delegados de los archiduques tendieron a ser crónicos; en efecto, tras el análisis de las cuarenta y ocho demandas de la monarquía durante el período 1600-1617 y 1625-1630, sólo en trece ocasiones los Estados de Artois estuvieron conformes con las cantidades inicialmente propuestas por el gobierno de Bruselas (es decir, el 27 por ciento); el resto (35 reuniones) acabaron en discordia, imponiéndose casi siempre la voluntad de los diputados. Esta actitud implicó una caída crónica en el rendimiento neto de los ingresos inicialmente demandados, que fue especialmente acentuada en los años anteriores a la Tregua con Holanda de 1609 (entre 1607 y 1610 el rendimiento osciló entre el 49,20 y el 35,71 por ciento) y sobre todo a partir del inicio de la guerra de los Treinta Años, con mínimos históricos en 1630 (44,72 por ciento) y muy especialmente en 1625 , año en el que sólo se recaudó el 33,69 por ciento de lo inicialmente solicitado ${ }^{11}$. Veamos el siguiente cuadro en el que comparamos las cantidades solicitadas, las realmente concedidas y el porcentaje final obtenido por los archiduques:

\footnotetext{
Los indices de rendimiento de los Estados de Artois fueron especialmente bajos si los comparamos con las ayudas y subsidios de otros Estados Provinciales de los Países Bajos. Como un ejemplo citamos el comportamiento de los Estados de Flandes para el periodo inicial de la guerra de los Treinta Años (1626-1636). Se reproducen las cantidades finalmente concedidas por los diputados.
}

\begin{tabular}{|c|c|c|c|c|c|}
\hline \multirow{2}{*}{$\frac{A N O O}{1626}$} & \multicolumn{2}{|c|}{ AYUDA ORDINARIA } & \multirow{2}{*}{$\frac{\text { SUBSIOIO EXTRAORDINARIO }}{\text { no se solicito }}$} & \multirow{2}{*}{$\frac{\text { TOTAL }}{1.080 .000}$} & \multirow{2}{*}{$\frac{{ }_{0} \text { SOBRE PETICION }}{100.00}$} \\
\hline & 1.080 .000 & florines & & & \\
\hline 1627 & 1.080 .000 & $\cdot$ & no se solicitó & 1.080 .000 & 100.00 \\
\hline 1628 & 1.080 .000 & $"$ & no se solicitó & 1.080 .000 & 100.00 \\
\hline 1629 & 1.080 .000 & $"$ & 300.000 & 1.380 .000 & 83,63 \\
\hline 1630 & 1080.000 & $"$ & 300.000 & 1.380 .000 & 77.96 \\
\hline 1631 & 1.080 .000 & $"$ & 360.000 & 1.440 .000 & * \\
\hline 1632 & 1.080 .000 & $"$ & 300.000 & 1.380 .000 & 76,66 \\
\hline 1633 & 1.080 .000 & & 100.000 & 1.180 .000 & 87.40 \\
\hline 1634 & 1.080 .000 & $"$ & 250.000 & 1.330 .000 & 78.23 \\
\hline 1635 & 1.080 .000 & $"$ & 400.000 & 1.480 .000 & 82,22 \\
\hline 1636 & 1.080 .000 & $"$ & 600.000 & 1.680 .000 & 84,00 \\
\hline
\end{tabular}

No hay datos porque desconocemos la solicitud inicial de la monarquia respecto el subsidio extraordinario.

FUENTE: BNP. manuscrits. Colbert, Flandre. 74. Recueil des aydes ordinaires et subsides extraordinaires de Flandre. accordés aux princes souverains du pays depuis lan 1626 jusques en 1642. 


\begin{tabular}{|c|c|c|c|}
\hline$A \tilde{N O}$ & CANTIDAD SOLICITADA & CANTIDAD CONCEDIDA & POR CIENTO \\
\hline 1600 & no consta & 300.000 libras & - \\
\hline 1601 & 300.000 libras & 300.000 libs. & 100,00 \\
\hline 1602 & 300.000 libs. & 300.000 libs. & 100,00 \\
\hline 1603 & 300.000 florines & 300.000 florines & 100,00 \\
\hline 1604 & 350.000 flrs. & 350.000 flrs. & 100,00 \\
\hline 1605 & 300.000 fles. & $300.000 \mathrm{flrs}$. & 100,00 \\
\hline 1606 & 400.000 libras & 330.000 libras & 82,50 \\
\hline 1607 & 546.000 flrs. & $230.000 \mathrm{f} / \mathrm{rs}$ & 42,12 \\
\hline 1608 & 630.000 flrs. & $310.000 \mathrm{flrs}$. & 49,20 \\
\hline 1609 & 680.000 flrs. & $330.000 \mathrm{flrs}$. & 48,52 \\
\hline 1610 & 840.000 flrs. & 300.000 firs. & 35,71 \\
\hline 1611 & 340.000 flrs. & $320.000 \mathrm{flrs}$ & 94,11 \\
\hline 1612 & 340.000 flrs. & $210.000 \mathrm{flrs}$ & 61.76 \\
\hline 1613 & 330.000 flrs. & $310.000 \mathrm{flrs}$. & 93,93 \\
\hline 1614 & $115.000 \mathrm{flrs}$ & $115.000 \mathrm{flrs}$ & 100,00 \\
\hline 1615 & $325.000 \mathrm{flrs}$ & 210.616 flrs. & 64,80 \\
\hline 1616 & 340.000 flrs. & 200.000 flrs. & 58,82 \\
\hline 1617 & 440.000 flrs. & $180.000 \mathrm{flrs}$. & 40,90 \\
\hline 1625 & $420.000 \mathrm{flrs}$ & $150.000 \mathrm{flrs}$ & 35,71 \\
\hline 1626 & 300.000 flrs. & $275.000 \mathrm{f} / \mathrm{rs}$ & 91,66 \\
\hline 1627 & 520.000 flrs. & $300.000 \mathrm{flrs}$ & 57.69 \\
\hline 1628 & 920.000 flrs. & $310.000 \mathrm{flrs}$ & 33,69 \\
\hline 1629 & 330.000 flrs. & $255.000 \mathrm{flrs}$ & 77,27 \\
\hline 1630 & 1.440 .000 flrs. & $644.000 \mathrm{flrs}$ & 44,72 \\
\hline
\end{tabular}

Las razones por las que se opusieron con tanta tenacidad los Estados de Artois a las pretensiones de Bruselas fueron muy variadas. Durante la grave crisis de subsistencia de comienzos del siglo XVII, fueron frecuentes las apelaciones de los Estados al hambre general como motivo de la rebaja de las pretensiones de los archiduques; en 1601, con ocasión de una petición de ayuda con motivo del sitio de Ostende, la asamblea representativa se quejaba de la extenuación de la tierra, los altos costos de los cultivos y el escaso aprovechamiento a causa de la caída del precio de los cereales ${ }^{12}$; asimismo, en la reunión de los Estados de 28 de octubre de 1604 , ante el intento del gobernador de la provincia, Federico de Berg, de aumentar los impuestos, se decía que Artois - como el resto de las provincias vecinas- sufría una extraordinaria pobreza y miseria ${ }^{13}$. En esa

Lettre d'accord des Etats d'Artois (5 de noviembre de 1601).

Recueil des aides... fols. 31-36, carta a los archiduques concediendo la ayuda de 300.000 florines. Arrás, 26 de noviembre de 1604. 
misma coyuntura, los diputados asistentes a la reunión de enero de 1606 se negaron inicialmente a admitir el pago de 300.000 florines, porque era una cantidad imposible de recaudar "con suplicación muy humilde que ruega a sus altezas la verdadera pobreza de la provincia de Artois»; en la siguiente reunión de los Estados (19 de febrero de 1606) se indicó que, si se aceptaban todas las pretensiones de los archiduques, era probable que estallaran disturbios en la provincia ${ }^{14}$.

A través de estas negociaciones es posible detectar nuevos episodios de malas cosechas y adversidades. En 1615 -pese a que la historiografia tiene el periodo como de prosperidad y buenos resultados agrícolas - los Estados reunidos en octubre aluden a una esterilidad general de los campos, que obligó a suspender el impuesto de un cuarto de centésimo sobre las tierras ${ }^{15}$. Otro episodio de esterilidad, asociado a epidemias en Lille y otras ciudades, se detecta en 1617, cuando los diputados expusieron que la cosecha sólo podía alimentar a un cuarto de la población y constataban una caída general de los impuestos asociados al vino, la cerveza y la tierra ${ }^{16}$.

Con el inicio de la guerra de los Treinta Años los indicios de pobreza como causa para la rebaja de las prestaciones fiscales tendieron a radicalizarse; en 1625 una solicitud de 420.000 florines fue rebajada hasta 150.000 a causa de la pobreza general de la provincia y al cese del tráfico comercial producido por la guerra con Alemania e Inglaterra ${ }^{17}$; al año siguiente los Estados denunciaron un hambre general ${ }^{18}$, acentuado por los excesos producidos por el alojamiento de siete compañias "que viven a costa de las ciudades, y toman granos y bestias, y exigen además forrajes sin participación y consentimiento de los Estados, con gran perplejidad de éstos" ${ }^{19}$. Asimismo, podemos detectar otros episodios de pobreza en

Ibidem, fols. 43v-45. Lettre d'accord fait par les Etats d'Artois, 21 de febrero de 1606. Si se aceptaba la ayuda de 300.000 florines «... on puissent ressentir quelque bruit et soullagement». Estos argumentos fueron aceptados por los archiduque por carta dirigida a los Estados desde Bruselas el 10 de marzo de 1606.

Esta crisis de subsistencia fue de gran intensidad. De hecho, las pretensiones iniciales de los archiduques de cobrar 220.000 florines fueron rebajadas a tan sólo 105.000 con el beneplácito de Bruselas (carta de aceptacion de la ayuda ordinaria de 1 de diciembre de 1615, en Ibidem, fol. 110).

Carta de los Estados a los archiduques Alberto e Isabel. Arrás, 12 de octubre de 1617

Recueil des aides..., fols. 121-124, carta de concesion de la ayuda ordinaria y subsidio extraordinario de 19 de diciembre de 1625; sin embargo, la principal queja de los Estados aludía a la publicación de un decreto lesivo para las operaciones con los comerciantes de las provincias vecinas.

Lettre d'accord des États d'Artois, de 14 de febrero de 1626; en ella se indica “... l'état miserable et deplorable de cette afligée province, dont les deux tiers des habitants sont si desnuéz et exteniéz de pauvreté qu'ils ne mangent du pain».

Recueil des aides..., fol. 133, sesión de los Estados de 8 de febrero de 1626. 
1628 (asociado, en opinión de los diputados, a la sobrecarga fiscal ${ }^{20}$ ) y en 1630 producido por el cese del comercio por la guerra de Alemania y al alto costo de los alojamientos de tropas.

Pero donde los Estados ejercieron una negociación implacable fue en la salvaguarda de los privilegios comerciales; fueron contadas las ocasiones en las que los diputados no aprovecharon la oportunidad para relacionar la concesión de ayudas y subsidios con la defensa del tráfico mercantil de la provincia con Francia, Inglaterra, Holanda e, incluso, el norte de Europa. El análisis de este interesante aspecto por parte de los Estados requeriría, ante la abundancia de documentación, una monografía; no obstante, podemos sintetizar las condiciones sobre el comercio dentro de los debates en la concesión de las ayudas y subsidios en el siguiente cuadro:

\begin{tabular}{|c|c|}
\hline AÑO & MATERIA DE LA NEGOCIACIÓN \\
\hline \multirow[t]{2}{*}{1601} & $\begin{array}{l}\text { Revocación de los decretos que prohibian a los mercaderes } \\
\text { comprar vinos en Francia. }\end{array}$ \\
\hline & $\begin{array}{l}\text { Defensa de los derechos de entrada y salida de productos de } \\
\text { la provincia. }\end{array}$ \\
\hline 1603 & Cese de imposiciones a los mercaderes. \\
\hline \multirow[t]{3}{*}{1604} & $\begin{array}{l}\text { Revocación de las contribuciones sobre las mercancias en- } \\
\text { trantes o salientes de Artois. }\end{array}$ \\
\hline & $\begin{array}{l}\text { Protesta por el impuesto de vino importado, que se conside- } \\
\text { raba excesivo ( } 4 \text { florines por pieza). }\end{array}$ \\
\hline & $\begin{array}{l}\text { Recordatorio de los Estados para que se levanten las nue- } \\
\text { vas tasas y gabelas sobre mercancias que entran y salen de } \\
\text { la provincia. }\end{array}$ \\
\hline $1605-1607$ & Levantamiento de los impuestos sobre mercancías. \\
\hline 1608 & $\begin{array}{l}\text { Revocación de los nuevos impuestos sobre la sal. } \\
\text { Anulación de los aranceles sobre mercancías importadas. }\end{array}$ \\
\hline 1609 & $\begin{array}{l}\text { Necesidad de consentimiento previo por los Estados ante } \\
\text { nuevos proyectos de impuestos sobre el tráfico mercantil. }\end{array}$ \\
\hline 1610 & Revocación del decreto sobre la sal. \\
\hline $1611-1617$ & Levantamiento de impuestos sobre mercancias. \\
\hline 1625 & $\begin{array}{l}\text { Anulación del decreto que limitaba las operaciones de los } \\
\text { mercaderes en las provincias vecinas. }\end{array}$ \\
\hline
\end{tabular}

(2) Reunión de los Estados de 5 de junio de 1628, donde se dice textualmente "la pauvreté extreme de cette pauvre province causée de tant de surcharges de années passées". 
Levantamiento de las imposiciones sobre mercancias importadas de Francia.

1626

Cese de cualquier imposición sobre entrada o salida de mercancias.

1628

Protesta por el aumento del "droit de tonlieu» ${ }^{21}$.

Solicitud al Gran Consejo de Malinas para que sean abolidas las medidas contra mercaderes extranjeros, sobre todo franceses.

Revocación del aumento de impuestos sobre mercancias ${ }^{22}$.

Queja sobre los derechos excesivos para la importación de lana procedente de España e Inglaterra.

Cese de los nuevos derechos sobre mercancías exportadas por tierra a Francia.

La polarización de las condiciones impuestas por los Estados en torno a la defensa de los intereses comerciales, viene a confirmar que la asamblea representativa de Artois estuvo ligada a una realidad social y económica básicamente urbana, donde las rentas comerciales primaban sobre cualesquiera otras por su creciente dinamismo. Además, como en el resto de las provincias tanto del norte como del sur, la representación política fundamental recayó en poder de los grupos urbanos ${ }^{23}$. Ello nos mueve a considerar si esta defensa de los privilegios comerciales frente a las necesidades recaudatorias de los archiduques tuvo un contenido, también, de cierta resistencia política; esto es, no sólo se luchó por el mantenimiento de un sistema comercial, sino como proyección de ello contra las tesis absolutistas de la monarquía y su política concreta lesiva a los intereses de la provincia. De hecho, los diputados de Artois se quejaron con

21 Según orden de 22 de noviembre de 1627, remitido a los oficiales de Saint Omer, se producia un importante incremento de impuestos sobre determinadas mercancías. Por ejemplo, los derechos sobre ciertas telas pasaba de 2 a 4 solis y la carga de Iprés también duplicó la carga fiscal. Mayores incrementos se observaron sobre el tráfico de lana.

2: Se refería a un decreto de 20 de octubre de 1622 denominado "tonlieu de Flandre", que, en opinión de los Estados de Artois, era perjudicial para el comercio, atentatorio contra los privilegios del pais y lesivo para los acuerdos de reconciliación. Además era contrario a las condiciones decretadas en la asamblea de los Estados Generales de los Paises Bajos de 1600 y a las reiteradas promesas de la princesa Isabel.

Pese a las protestas de los Estados, el gobierno de Bruselas se opuso a rebajar el ctonlieu de Flandre", exponiendo además la comprensión de otras provincias a estas medidas (Carta de la princesa Isabel a los Estados de Artois, Bruselas, 14 de diciembre de 1628).

23 Sobre el caso holandés, véase el estudio de J. DHONT, Estates or powers. Essays in the parliamentary history of the Southern Netherlands from the XIlth. to the XVIIIth. century, Heule, 1977. 
frecuencia de que los intereses políticos y estratégicos de los Habsburgo impedian las relaciones comerciales ${ }^{24}$ naturales con las provincias del norte, Inglaterra y Francia ${ }^{25}$.

\section{FINANCIACIÓN DE LAS AYUDAS. FÓRMULAS FISCALES DE PAGO Y REPARTIMIENTO}

El análisis de la fiscalidad y de las fórmulas de pago constituye quizá uno de los medios más eficaces para evaluar las características sociales y poder político de una asamblea representativa, sobre todo en el caso de Artois donde el creciente ascenso de los intereses urbanos tenían que conjugarse con otros no menores del mundo rural. Ello se dejó sentir en el tipo de fiscalidad diseñada para el pago de ayudas y subsidios, con una tendencia al equilibrio entre los impuestos que gravaban el consumo, la propiedad urbana, los derechos comerciales y la propiedad de la tierra. Aunque se observa una tendencia a hacer recaer la presión fiscal sobre el consumo y la tierra en beneficio de los intereses oligárquicos urbanos (propietarios de inmuebles y comerciantes).

La evolución del tipo de carga fiscal confirma lo indicado. Los primeros repartimientos de ayudas del siglo xvil se apoyaron en la fiscalidad sobre

En los Estados de Flandes la actitud de sus diputados fue prácticamente análoga a los de Artois en la defensa de los intereses comerciales de la provincia durante las negociaciones para la concesión de las ayudas y subsidios. Veamos algunos ejemplos del periodo 1635-1639, que ratifican la existencia de una misma politica comercial en el seno de los Estados Provinciales de los Paises Bajos:

\begin{tabular}{|c|c|}
\hline ANO & MATERIA DE NEGOCIACION \\
\hline 1635 & $\begin{array}{l}\text { Otorgamiento de la ayuda ordinaria bajo condicion del levantamiento de todos los am- } \\
\text { puestos sobre el vino. } \\
\text { Levantamento del impuesto de } 4 \text { libras de gros por tonel de vino mportado de } \\
\text { Francia. }\end{array}$ \\
\hline 1637 & $\begin{array}{l}\text { Derogacion del impuesto sobre el vino importado de Francia } \\
\text { Cese de los impuestos sobre mercaderias importadas por los puertos de Flandes. } \\
\text { Privilegio de exencion de licencia por } 10 \text { dias a los mercaderes de Suecia y otros pa- } \\
\text { ses neutrales. }\end{array}$ \\
\hline 1638 & $\begin{array}{l}\text { No crear nuevos impuestos sobre las mercancias entrantes o salientes por lerra y } \\
\text { mar de Flandes. }\end{array}$ \\
\hline 1639 & Concesion de una ayuda a cambio de no situar nuevos impuestos sobre mercaderias \\
\hline $\begin{array}{l}\text { FUENTE: } \\
\text { de Flandro. }\end{array}$ & JP. manuscrits. Colberl. Flandre. 74. Recueil des aydes ordmames e! subsides extraordmames \\
\hline
\end{tabular}

Lettre d'accord des Etats d'Artois. de 20 de mayo de 1609. También hay alusiones al comercio con Inglaterra y Francia en la respuesta de los archiduques a la carta anterior (Mariemont. 26 de mayo de 1609). 
la propiedad, especialmente la inmobiliaria; en efecto, las dos ayudas concedidas en $1600^{26}$ se pagaron de la siguiente manera: la primera mediante un reparto directo sobre la Iglesia, la nobleza y las ciudades ${ }^{27}$; $\sin$ embargo, la segunda fue con cargo a un impuesto de un centésimo ${ }^{28}$ sobre todo los inmuebles de la provincia, que venia a equivaler al 20-25 por ciento de la renta bruta de los mismos ${ }^{29}$, medio centésimo y cuarto sobre "chimeneas" y diversas tasas sobre el vino y la cerveza ${ }^{30}$. La presión fiscal debió alcanzar cotas muy elevadas, puesto que los diputados se quejan de que ya se estaban pagando otros impuestos creados para financiar el sitio de Cambrai ${ }^{31}$.

Tan enorme presión fiscal y la exigencia de los archiduques que ambas ayudas se efectuaran en un sólo pago, puede explicar el interés de los Estados en impedir el fraude y la proliferación de exentos. El sistema de recaudación se articulaba a través de una red de receptores y cogedores particulares, así como ciertos de oficiales de los burgos y ciudades; cada núcleo tenía asignada una cantidad giobal (estaba prohibida cualquier segregación o división de la carga fiscal dentro de cada ciudad) que debía ser entregada a las autoridades del municipio para su posterior centralización ${ }^{32}$. Asimismo, se especificaba que los impuestos tendrian un carácter universal afectando - dice textualmente la resolución de los Estados - «a todas las personas, indiferentemente eclesiásticos, seculares, privilegiados y no privilegiados, hombres de guerra, de corte, arzobispos, obispos,

\footnotetext{
En julio de 1600 los Estados concedieron una ayuda de 40.000 libras y en diciembre del mismo año otra de 300.000 .

El reparto siguió la siguiente proporcionalidad: la Iglesia, 10.000 libras $(25 \%)$, la nobleza $10.000(25 \%)$ y las ciudades $20.000(50 \%)$.

se El centésimo o uno por ciento tenia una larga tradición en la fiscalidad de los Estados Provinciales. Por ejemplo, en 1569 el duque de Alba solicitó de los Estados un centésimo sobre las rentas, un vigessimo ( 5 por ciento) de la venta de inmuebles y un decimo ( 10 por ciento) sobre las ventas (G. PARKER, El ejército de Flandes y el Camino Español. 1567-1659. Madrid, 1991, págs. $179-180$ ). La bibliografia sobre el centésimo es muy abundante y remito a los comentarios de las páginas mencionadas.

24 Dicho impuesto fue aprobado, sin duda, por los Estados porque era poco lesivo para los propietarios, todavez que la carga impositiva neta recayó "les occupeurs, censsiers et louagiers", aunque los propietarios eran responsables en caso de impago (Recueil des aides..., Lettres d'accord par les Estats du pays et comté d'Artois aux archiducs Albert et Isabelle d'un ayde de 300 milles livres pour une année commenceant le $1^{\circ}$. de novembre $1600 \ldots$. Arrás, 2 de diciembre de 1600).

El lot de vino fue gravado con doce deniers y el tonel de cenveza de 40 lots en cuatro soldes.

La aportación de Artois para el sitio de Cambrai se situó en torno a los 200.000 florines.

Por la documentación manejada no cabe ninguna duda de que las cantidades otorgadas por los Estados eran contabilizadas administrativamente por la cámara de cuentas de Lille.

Sobre el sistema de recaudación de las ayudas y subsidios por los Estados de Artois, Recueil des aides... fols. 3-7v; asimismo, las resoluciones de los Estados Generales de los Paises Bajos de 1600 , L. Gachard, Actes..., op. cit.
} 
prelados, capítulos, universidades, caballeros ${ }^{33}$, nobles, Consejos de Estado, Privado y Hacienda, Gran Consejo, Cámara de Cuentas ${ }^{34} \ldots$ sin exceptuar nadie por privilegiado que sea". Las únicas exenciones contempladas por los Estados se referían a las cuatro órdenes monásticas mendicantes, la Compañía de Jesús y los capuchinos. $Y$ además advertian que "con la carga expresa que si se exenta a los caballeros se deducirá parecida suma de la ayuda, y así será deducida».

A partir de la reunión de los Estados en noviembre de 1601, los diputados introdujeron algunas modificaciones en el reparto del centésimo sobre los inmuebles, lo que venía a confirmar la imposibilidad de los inquilinos y censatarios de pagar ellos exclusivamente el impuesto; se tendió, pues, a una racionalización ${ }^{35}$ en la distribución de la carga impositiva entre propietarios e inquilinos: en los campos los censatarios pagarían dos tercios y el propietario el tercio restante, en tanto en las ciudades el impuesto se repartiría por partes iguales entre propiedad e inquilinato. No obstante, la responsabilidad en caso de impago sería del propietario, una condición que desde ese momento permanecerá inmutable.

El impuesto sobre los inmuebles no debió percibirse en la ayuda ordinaria de 1603. Tras el éxito militar en Ostende, el impuesto vuelve a aparecer pero en una cuantía menor (dos cuartos y medio de centésimo) debido a la adversas condiciones que atravesaba la provincia en esa ocasión ${ }^{36}$. A partir de ese momento hasta el fin de la tregua con los holandeses el impuesto sobre los inmuebles se menciona de manera indirecta bajo el epígrafe «impuestos vigentes"; es posible que en ocasiones excepcionales dejara de percibirse, pero en la mayoria hay que sospechar que seguía vigente, todavez que los diputados exponían con frecuencia en los debates el enorme peso fiscal del "centiesme»: disminuía la renta de los propieta-

\footnotetext{
En el capitulo de caballeros siempre se incluyeron los de la orden del Toisón de Oro.

Sobre los privilegios fiscales de los miembros de las Cámara de Cuentas, el reciente estudio de A. Vandenbulcke, Les Chambres des Comptes des Pays-Bas espagnols. Bruselas, 1996 , especialmente las págs. 161-162. Por lo común, cuando un nuevo impuesto era creado para el pago de las ayudas y subsidios, los oficiales de la Cámara intentaban que sus privilegios de exención fiscal fueran confirmados, aunque siempre contaron con la oposición de los ciudades y los Estados Provinciales.

"Los diputados ordinarios de dichos Estados lo encontrarán conveniente para una más cómoda y racional percepción", en Recueil des aides..., fols. 15-16. Era la constatación de la inviabilidad del sistema anterior de cargar el impuesto exclusivamente sobre los inquilinos.

36 En la reunión de los Estados de 28 de octubre de 1604 los diputados afirmaban «... que la dite province d'Artois soit extremement diminuée de moyens et languissante encore par les guerres dernières et à cause des grandes charges et subsides y imposés pour subvenir aux aydes des années passées".
} 
rios al menos en un veinte por ciento, no se contemplaba la deducción de gastos, las demoras de los inquilinos eran frecuentes y, sobre todo, que los titulares debian de hacer frente a los casos de insolvencia ${ }^{37}$.

Con el inicio de la guerra de los Treinta Años, el impuesto sobre inmuebles tendió a radicalizarse, esto es, debieron revisarse el valor de los inmuebles con el objeto de optimizar el rendimiento fiscal de los mismos. Hasta 1629 no se alude a ninguna operación de revisión catastral, pero a partir de las reuniones de 1630 siempre se hizo constar que el impuesto era proporcional al valor real del edificio ${ }^{38}$.

La segunda fuente de financiación para el pago de las ayudas y subsidios fue la tierra; la base de esta prestación se apoyaba en la existencia de las denominadas "ocho ayudas campestres" que, a tenor de la documentación manejada hasta ahora, era el impuesto básico de ciertas zonas rurales $y$, al parecer, el sustitutivo de las cargas sobre los inmuebles del mundo urbano. Sin embargo, a partir de 1605 -coincidente con el notable incremento de las ayudas ordinarias y la generalización de los subsidios extraordinarios - el impuesto sobre las tierras (hasta entonces repartido sólo en algunas zonas de la provincia) tendió a generalizarse y a incrementarse. Ya en la reunión de los Estados de 10 de enero de 1606, los diputados propusieron la creación de un nuevo impuesto de medio centésimo "sobre todas las tierras de Artois", sin excepción alguna, afectando a las propiedades de la iglesia y la nobleza ${ }^{39}$.

Sin embargo, el medio centésimo propuesto fue inmediatamente reducido a un cuarto ante las posibles protestas que podría generar el mantenimiento del medio centésimo ${ }^{40}$. A partir de ese momento, hemos podido observar un proceso de depuración y clarificación del impuesto sobre las tierras y las heredades, lo que viene a confirmar la enorme complejidad del mismo. En efecto, la sesión de los Estados de 25 de septiembre de 1606 fue capital en este sentido: el medio centésimo se

Por ejemplo, estos problemas del impuesto sobre inmuebles tuvieron especial relevancia en los debates de los Estados de 8 de octubre de 1607, donde los diputados expusieron a los archiduques que los "censsiers et louagiers" no pagaban su parte del impuesto, lo que implicó frecuentes ruinas entre los propietarios.

38 Lettre d'accord des États d'Artois, de 5 julio de 1630 y Lettre d'acceptation des archiducs, de 6 de agosto de ese mismo año.

Recueil des aides... fols. $37 \mathrm{v}-40 \mathrm{v}$.

:4) Ibidem. Lettres d'accord fait par les États d'Artois, de 21 de febrero de 1606 . Esta propuesta no fue aceptada inicialmente por los archiduques (Bruselas, 10 de marzo de 1606), aunque luego se confirmó tras nuevas negociaciones (cartas de los Estados de 21 de marzo y de los archiduques de 10 de abril de 1606). 
consolidó en aquellas zonas que habian estado exentas de las "tailles champestres", estableciéndose una fórmula por la que tanto el propietario como el ocupante pagarían el cincuenta por ciento de la carga contributiva; en el caso de las villas de la jurisdicción de Saint Omer que no pagasen la talla campesina ordinaria, aún manteniéndose el mismo porcentaje del medio centésimo, la carga tributaria tendría un tratamiento diferente: un tercio correspondería al propietario y los dos tercios restantes al ocupante de la tierra ${ }^{41}$.

Desde ese momento, el impuesto sobre la tierra se va a erigir en una fuente ordinaria para la financiación de las prestaciones de los Estados; en 1607 el subsidio extraordinario de 30.000 florines fue pagado exclusivamente con un cuarto de centésimo sobre todas las tierras y heredades de la provincia ${ }^{42}$. Este cuarto se mantuvo inalterable hasta 1609; sin embargo, tras la firma de la Tregua de 1609, se elevó a un tercio en 1610 y 1611 para financiar los gastos de licenciamiento de parte del ejército; entre 1612 y el comienzo del conflicto de los Treinta Años, sin duda aprovechando los buenos resultados agrícolas, el impuesto se elevó a un medio (salvo el año 1615 que coincidió con una esterilidad general). No obstante, los mayores incrementos se produjeron a partir del estallido del conflicto, cuando se alcanzó la cota de los tres cuartos, porcentaje que se consolidó durante los años 1625 a 1630.

Serán, sin embargo, los impuestos sobre el consumo y las transacciones comerciales el eje en el que descansará la financiación de las ayudas y subsidios de los Estados de Artois. Ello era lógico por la facilidad en la percepción de la imposición indirecta, porque este tipo de impuestos se encontraban muy asentados en la realidad económica de las provincias $y$, sobre todo, porque las autoridades municipales - responsables finales ante los Estados del pago de las ayudas y subsidios- poseían una amplia experiencia sobre este tipo de impuestos, así como una burocracia municipal acostumbrada a su gestión y percepción. De hecho, otros Estados Provinciales de los Paises Bajos utilizaron idénticas fórmulas fiscales para el pago de sus prestaciones fiscales, especialmente sobre vino ${ }^{43}$, cerve-

Existe un interesante y minucioso terrier de Saint Omer (con 229 folios) correspondiente al año 1631 en BNP. manuscrits, Colbert. Flandres, 87, a continuacion del Recueil des aides..

Lettres d accord des États d'Artois pour le payememt du subside extraordinaire de 30.000 florins (Arrás, 15 de febrero de 1607).

43 Acerca del impuesto sobre vinos de los Estados Provinciales de Lille, Douai y Orchies, BNP, manuscrits, Colbert. Flandre. 152, État du compte de limpost levé à Lille sur le vin par les Etats de Lille, Douai et Orchies. 
EVOLUCIÓN DE LAS AYUDAS DE LOS ESTADOS DE ARTOIS, $1600-1630$

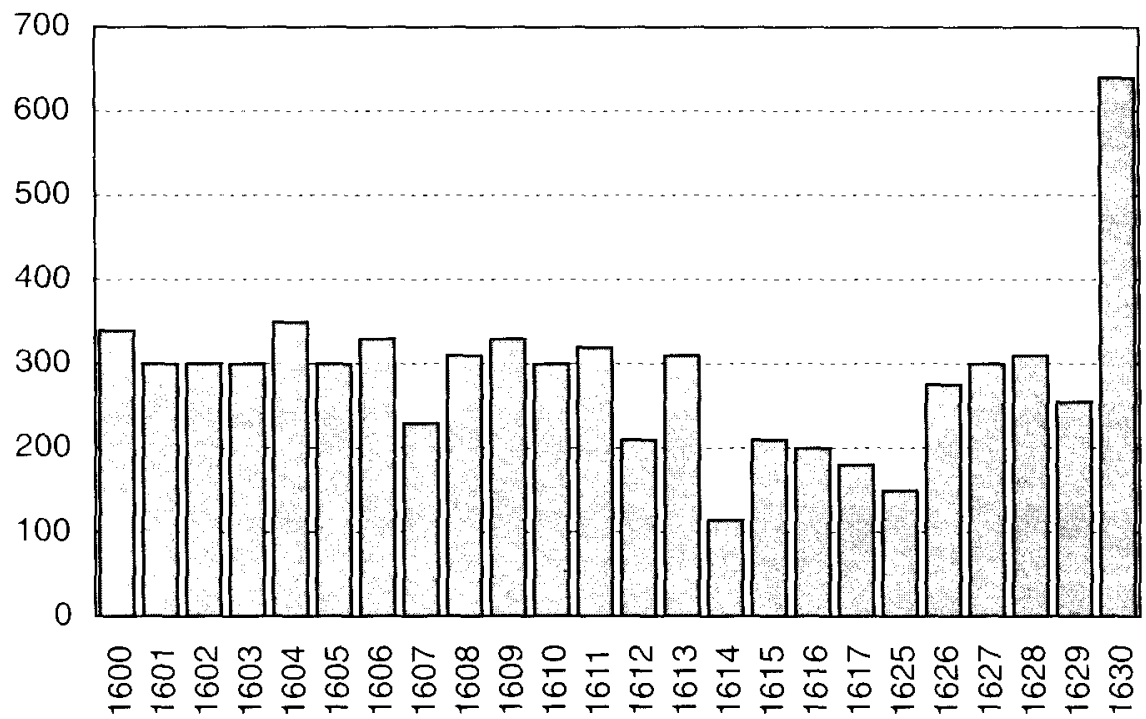

En miles de florines.

EFICACIA DE LAS DEMANDAS FISCALES ANTE LOS ESTADOS DE ARTOIS (PORCENTAJE FINAL SOBRE LAS CANTIDADES SOLICITADAS)

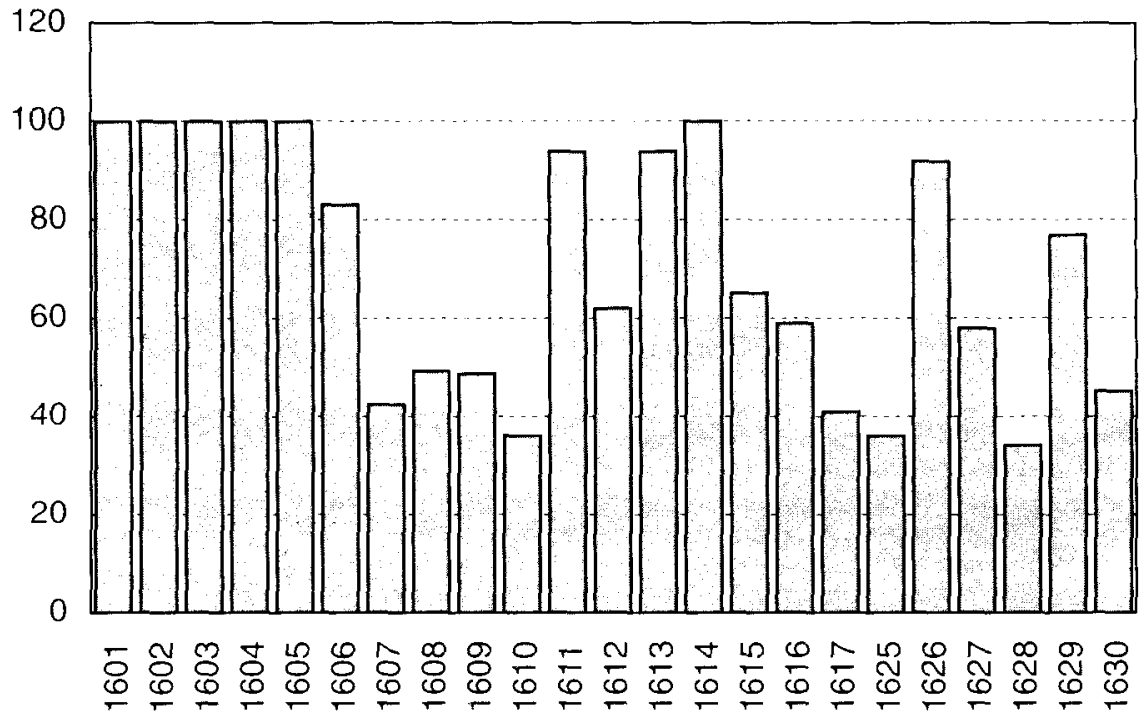


EVOLUCIÓN PORCENTUAL DE ALGUNOS IMPUESTOS CREADOS POR LOS ESTADOS DE ARTOIS PARA EL PAGO DE AYUDAS Y SUBSIDIOS, 1600-1615
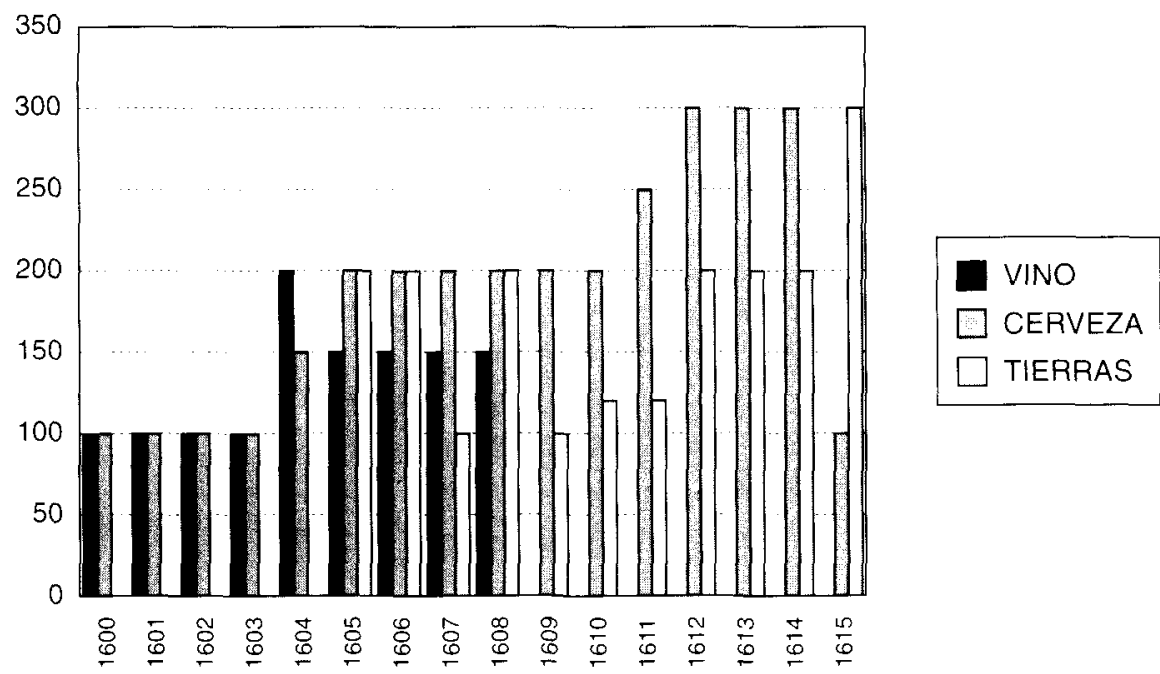

Vino y cerveza, $1600=100$. Impuesto sobre tierras, $1607=100$.

EVOLUCIÓN DEL “CENTIESME» SOBRE TIERRAS Y HEREDADES (1605-1630)

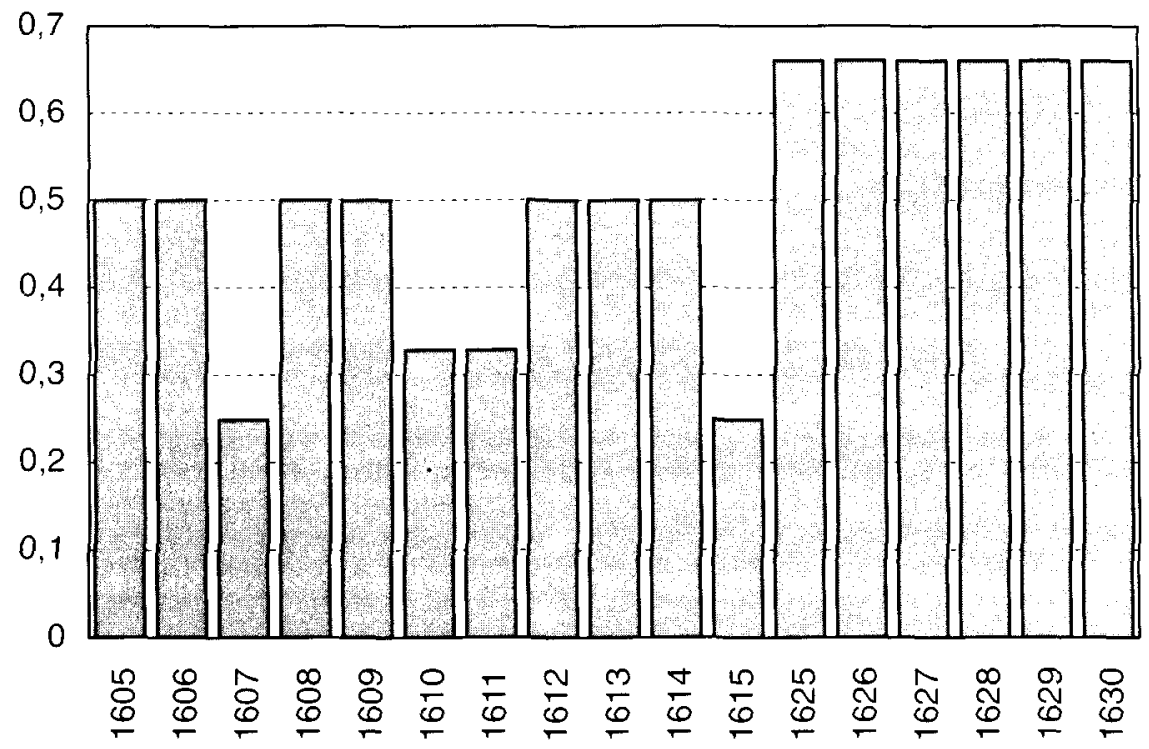


zas, aguardientes ${ }^{44}$, pañería ${ }^{45}$, molienda de cereales ${ }^{46}$ y derechos de tránsito ${ }^{47}$.

En el caso de los Estados de Artois, las ayudas y subsidios se apoyaron inicialmente en los impuestos sobre el vino y la cerveza ${ }^{48}$. En 1600 se impuso un sobreprecio de doce deniers al vino y cuatro solis para la cerveza; en 1604 con la aprobación del primer subsidio extraordinario del siglo XVII los impuestos se elevaron, especialmente para la cerveza que alcanzó los seis solis por tonel. Desde ese momento el incremento de los impuestos sobre estos productos no hizo sino crecer de una manera ininterrumpida; hacia 1606 los Estados protestaron por la excesiva presión fiscal ejercida sobre el vino y la cerveza, que podría elevarse a más del 25 por ciento al combinarse varios impuestos, especialmente en el vino importado que sufría fuertes aranceles ${ }^{49}$.

En 1611 el vino sufre una nueva subida de 15 deniers y el tonel de cerveza otros 4 solis. Su incremento será ininterrumpido desde ese momento. A estos impuestos se sumaron otros sobre la "doble cerveza" y el aguardiente, que comienzan a aparecer en el debate de los Estados en noviembre de $1609^{50}$. Inicialmente se cargaron 4 solis por tonel de doble cerveza y 30 por el lot de aguardiente; éste apenas si modificó su gravamen hasta el comienzo de la guerra de los Treinta Años, en tanto el tonel de doble cerveza no cesó de crecer a partir de 1611 ( 6 solis), llegando a los 8 en 1616. Otros impuestos sobre el consumo descansaron en la sal, los cereales e, incluso, la venta de caballos, bueyes y otras bestias.

Con frecuencia, los Estados tuvieron que recurrir a suscribir préstamos con particulares para hacer frente al pago de las ayudas. Este aspecto es

\footnotetext{
Ibidem. 153-1. Etat du compte de la somme des imposts sur le brandevin pour les États de Lille. Douai et Orchies.

Ibidem, 147, Etat du compte sur les bières et draps vendus en la ville de Lille et fauxbourgs d'icelle. El producto de los impuestos se repartian al cincuenta por ciento entre la ciudad y la asamblea representativa.

to Caso de los Estados de la provincia de Flandes para el pago de un subsidio extraordinario de 600.000 florines concedido en 1630 (BNP, manuscrits, Colbert. Flandre, 74).

1. Se trataba de un impuesto que afectaba básicamente a las mercancias al transitar sobre los caminos. Según una relación de la ciudad de Lille (Ibidem, 148) se establecían ciertos tipos en función de la capacidad de carga (carros y carretas alemanas, carretas ordinarias, caballo con carga, etc.). Sólo quedaban exentos los que traian granos a los molinos de la ciudad.

: Se aplicaba sobre dos medidas: el lot para el vino y el tonel (de 40 "lots") para la cerveza.

44. Protesta de los Estados reunidos el 21 de febrero de 1606. En 1607 los diputados expresaron su oposición a los impuestos sobre el vino y cerveza, doblemente gravados en la primera compra y en el consumo.

Recueil des aides, fols. $78 \mathrm{v}-80$. Lettres d'accord des États de 24 de noviembre de 1609 kara la ayuda de 130.000 florines.
} 
básico porque la obtención del crédito no parece que fuese difícil entre una oligarquía comercial deseosa de beneficiarse de altos tipos de interés. Ya en 1600 los Estados aluden a que se había contraido un préstamo de 40.000 libras; en 1604, con ocasión de un subsidio extraordinario de 50.000 florines, los diputados, no pudiendo reunir la cantidad, solicitaron a los archiduques la posibilidad de un préstamo que fue obtenido al catorce por ciento de interés ${ }^{51}$. El recurso al crédito debió extenderse a partir de 1621; el subsidio extraordinario de 150.000 florines, concedido en diciembre de 1625 , fue financiado en parte con recurso al crédito, aunque carecemos del tipo de interés pagado. De 1630 tenemos dos preciosas referencias sobre el recurso al crédito por parte de los Estados; la primera, que uno de los prestamistas más importantes era el clero de la provincia; la segunda que, en vísperas de la entrada de Francia en el conflicto de los Treinta Años, los Estados de Artois tuvieron que pagar un interés del 16 por ciento para financiar el pago de 350.000 florines ${ }^{52}$.

\section{EVOLUCIÓN Y DESTINO DE LAS AYUDAS Y SUBSIDIOS}

La coyuntura de estos años iniciales del siglo xVII (guerra contra las provincias del norte, las secuelas de la Tregua de 1609 y las primeras fases del conflicto de los Treinta Años) condicionó decisivamente la evolución de las prestaciones fiscales de los Estados de Artois de una forma casi mecánica ${ }^{53}$. Entre 1600 y 1609 la asamblea representativa concedió de manera efectiva un total de 3.090 .000 florines $^{54}$, de los que $170.000 \mathrm{co-}$ rrespondieron a subsidios extraordinarios.

El 14 por ciento de interés parece ser el vigente a principios del siglo XVII para este tipo de préstamo. De hecho, tenemos varias referencias de los Estados de Artois donde se alude a que la provincia habia contraido varios préstamos a ese interés. Por ejemplo, en la reunión de los Estados de 28 de octubre de 1604 , protestando de las peticiones fiscales de los archiduques, se dice que la provincia había anticipado 20.000 florines financiados con un crédito al 12 por ciento (Recueil des aides..., fol. 36).

La referencia a este tipo de interés en Recueil des Aides... fol. 187v, Carta de aceptación por la princesa Isabel de una ayuda de los Estados de Artois (Bruselas, 10 de mayo de 1631).

Los estudios dedicados a los problemas de este periodo son lógicamente muy abundantes. Además de los trabajos citados a lo largo de este estudio, con carácter general, G. PARKER, Spain and the Netherlands, 1559-1659: Ten Studies, 1979. J. AlCALA-Zamora, España. Flandes y el mar del Norte, 1618-1639. Barcelona, 1975, I. A. A. THOMPSON, Guerra y Decadencia. Barcelona, 1981. Una reciente visión de conjunto del gobierno de los Paises Bajos en $\mathrm{H}$. COPPENS y K. VAN HONACKER (eds.). Symposium sur les institutions du gouvernement central des Pays-Bas Habsbourgeors. Bruselas, 1995.

Las pretensiones iniciales de la monarquía durante ese periodo de 1600-1609 se elevaron a 4.146.000 florines. 
La ayuda concedida en julio de 1600 (40.000 libras) se otorgó para el sostenimiento de 1.000 soldados de infantería y tres compañias de caballería, bajo la condición de que abandonaran la provincia en un plazo de 15 dias; la de diciembre de ese año (300.000 libras) tuvo como objetivo colaborar para el mantenimiento de 10.000 soldados de infantería y 15 compañías de tres mil caballos; los diputados, ante el temor de disturbios y amotinamientos del ejército, pusieron como condición que serían los propios Estados los encargados de pagar durante seis meses a las tropas acantonadas en Artois ${ }^{55}$; además, no se consentirian alojamientos de más de una noche y sin derecho de las tropas a tomar pan y cerveza (en caso de gastos extraordinarios del ejército, éstos serían deducidos de la ayuda ordinaria de los Estados).

Aunque, como señala Parker, Ambrosio de Espínola tenía un crédito personal ilimitado, la campaña para la reconquista de Ostende significó para los Estados de Artois un desembolso de 950.000 florines ${ }^{56}$. La alta fiscalidad desplegada en una coyuntura económica especialmente adversa (disminución de los precios agrícolas y caida del tráfico comercial) junto a la invasión holandesa, obligó a los diputados a "suplicar a sus altezas moderen en el porvenir la demanda de estas ayudas tan elevadas" ${ }^{57}$. Entre 1605 y 1609 las ayudas ordinarias oscilaron entre 300.000-150.000 florines y los subsidios entre 30.000-10.000, siempre con la finalidad de financiar los gastos militares. Sin embargo, estas cantidades sufrían con frecuencia importantes deduciones por gastos anticipados por los Estados; así, en $1605^{58}$ se sustrajeron 3.320 florines que se dieron al regimiento del coronel Patrice, gastos de mantenimiento de 400 hombres de la leva realizada por el capitán Torres y, sobre todo, 10.401 para los ejércitos que acudieron a sofocar a los amotinados en Roermond.

La conclusión de este incremento de la presión fiscal durante el período anterior a la Tregua de 1609 fueron las constantes protestas de los diputados. En octubre de 1607 se produjo uno de los debates más tensos entre los Estados y los archiduques; aquéllos recordaron que la ayuda ordinaria mensual era de 25.000 florines, que en octubre de 1607 se había repartido un subsidio extraordinario de otros 50.000 para el mantenimien-

En realidad, los Estados de Artois sostuvieron cuatro regimientos completos. La ayuda se recaudó en plazos trimestrales.

st Recueil des aides... fols. 13v-17, reunión de los Estados de 5 de noviembre de 1601 , donde se especificaba que la ayuda iba destinada especificamente para cl'expugnation de la ville d'Ostende".

Subsidio extraordinario de 50.000 florines de 17 de junio de 1604

\$\$ Recueil des aides.... reunión de los Estados de 10 de enero de 1606 para la concesión de una ayuda de 300.000 florines, fols. $37 \mathrm{v}-40 \mathrm{v}$. 
EVOLUCIÓN COMPARADA DE LAS APORTACIONES DE LOS ESTADOS DE ARTOIS Y FLANDES, 1626-1635

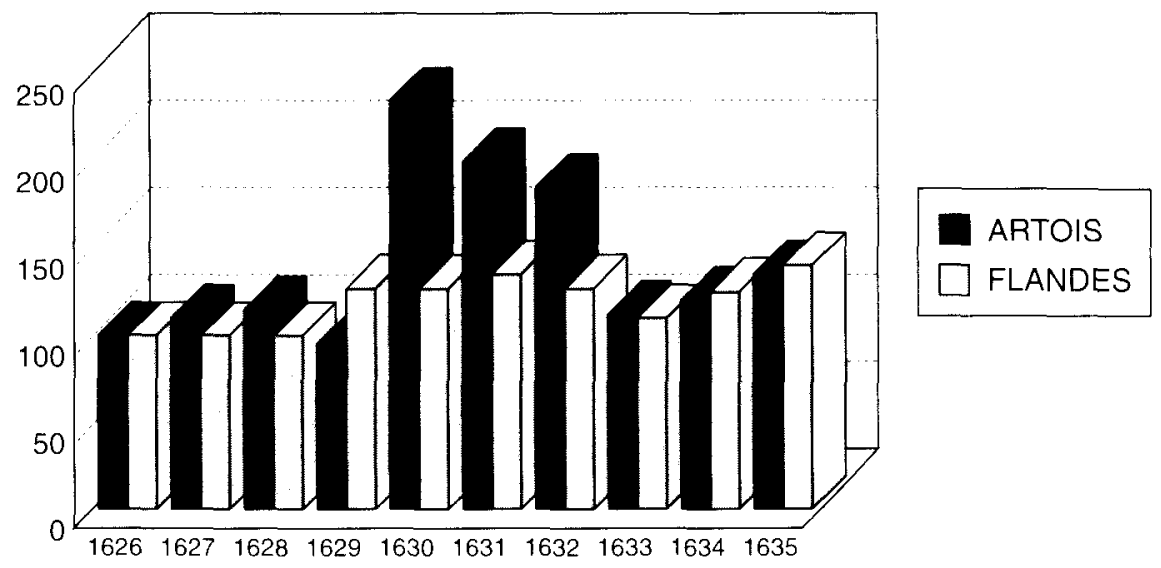

Año $1626=100$

DISTRIBUCIÓN DEL SUBSIDIO EXTRAORDINARIO DE 1635 (APORTACIONES DE LOS ESTADOS PROVINCIALES)

FLANDES 500

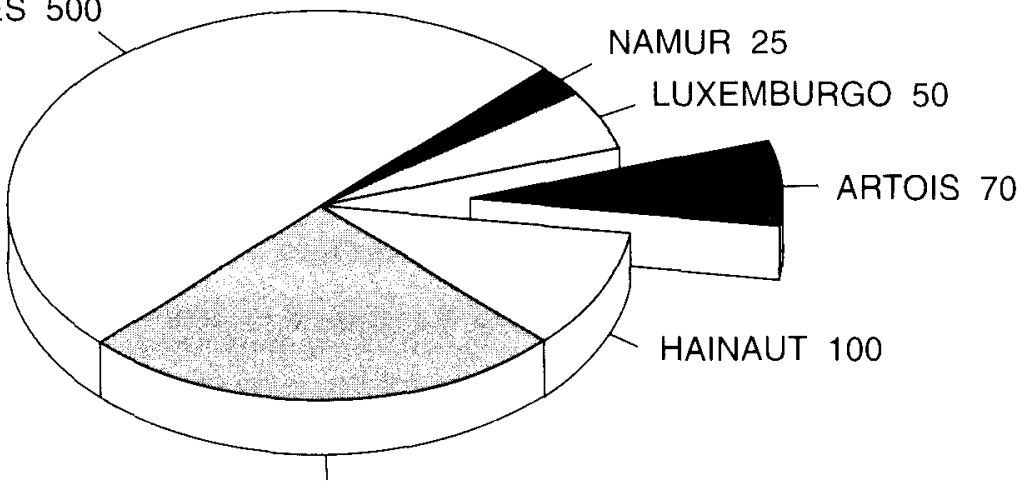

BRABANTE 250

En miles de florines 
to "de la gendarmerie repartie par le pays d'Artois durant c'est hyvert (sic)", que la guerra con Francia había arruinado el comercio, que el asalto a Cambrai consumió 120.000 florines... ${ }^{59}$. La solución inmediata propuesta fue solicitar que la provincia fuese descargada del mantenimiento de tres compañías de caballería y, a la larga, obtener una paz general.

Con el establecimiento de la Tregua de 1609 , los gastos militares volvieron a reproducirse bajo el pretexto de licenciar una parte del ejército, que consumió 150.000 florines de ayuda y 50.000 de subsidio. En 1610, con la paz, los Estados tuvieron que aportar otros 40.000 florines de extraordinario para sostener los gastos de la casa de los archiduques (además, de la ayuda ordinaria evaluada en trescientos mil). Desde ese momento hasta el inicio de la guerra de los Treinta Años se produjo un cierto alivio de las cantidades solicitadas desde Bruselas, pero la media anual no bajó en ningún caso de los 140.000160.000 florines con la finalidad de mantener la seguridad de la provincia. De hecho, el esfuerzo realizado hasta ese momento se evaluó en una deuda de dos millones de florines a altos tipos de interés (quizá el doce por ciento) ${ }^{60}$.

Con el estallido del conflicto de los Treinta Años, de nuevo las aportaciones de los Estados sufrieron constantes incrementos, pese a que éstos lograron importantes rebajas respecto las iniciales pretensiones del gobierno de Bruselas. En efecto, las máximas propuestas correspondieron a 1628 con un total de 960.000 florines (rebajados a 450.000 ) y 1630 (el gobierno de la princesa Isabel llegó a solicitar casi millón y medio, aunque solo obtuvo 644.000 , esto es, el 44,7 por ciento). Durante este periodo de 1625 a 1630, los Estados financiaron: en 1625 un tercio de 600 hombres, en 1626 el mantenimiento de siete compañías de caballería y otras dos más en tránsito, en 1627 las mencionadas siete compañías y los gastos provocados por "la levée des chariots et soldats envoyez au Camp de Brède " ${ }^{61}$, en 1628 se menciona que la provincia mantenía a su costa cuatro regimientos y 15 compañias de caballería ${ }^{62}$,

\footnotetext{
Recueil des aides..., fols. 61-65, sesión de los Estados de 8 de octubre de 1607.

Reunión de los Estados de 16 de noviembre de 1614. Se aprovechó la ocasión para recordar a Bruselas que en ese año los Estados mantenian:

- 6 compañias de infantería

- el regimiento del señor de la Motterie 1 compañia de caballería.

Sobre el significado estratégico y económico de la toma de Breda, entre otros, $R$. A. StRADLing, Europa y el declive de la estructura imperial española, 1580-1720. Madrid, 1992, especialmente págs. 84 y ss.

6? Ese año los Estados reunidos el 24 de noviembre solicitaron formalmente "que cessent universellement par tout les pays toutes sortes de tailles, contribution de service des gens de guerre, fourrages, fortifications, chariots, pionniers et autres charges quelconques... ensemble toutes charges de passage et repassage de gens de guerre".
} 
en 1629 hemos detectado la presencia de tropas capitaneadas por Vázquez Coronado, así como numerosos gastos destinados al socorro de Bois-le-Duc, en 1630 se mantuvieron - al menos- diez compañias de infantería irlandesa y dos valonas, y se hizo constar que los Estados retendrían los gastos ocasionados por los excesos cometidos por una compañía de caballería con sede en Cambrai.

Comparativamente, el esfuerzo financiero de los Estados de Artois durante el período 1626-1635 fue extraordinario. Valga para evaluarlo el siguiente cuadro que, con base 100 para 1626, compara la evolución de las ayudas y subsidios de Artois con los de la provincia de Flandes:

Evolución porcentual de las aportaciones de los Estados de Artois y de Flandes, 1626-1635 (1626=100)

\begin{tabular}{ccc}
\hline AÑO & ESTADOS DE ARTOIS & ESTADOS DE FLANDES \\
\hline 1626 & 100,0 & 100,0 \\
1627 & 109,5 & 100,0 \\
1628 & 112,7 & 100,0 \\
1629 & 92,7 & 127,7 \\
1630 & 234,1 & 127,7 \\
1631 & 200,0 & 133,3 \\
1632 & 184,0 & 127,7 \\
1633 & 112,7 & 109,2 \\
1634 & 118,1 & 123,1 \\
1635 & 134,5 & 137,0 \\
\hline
\end{tabular}




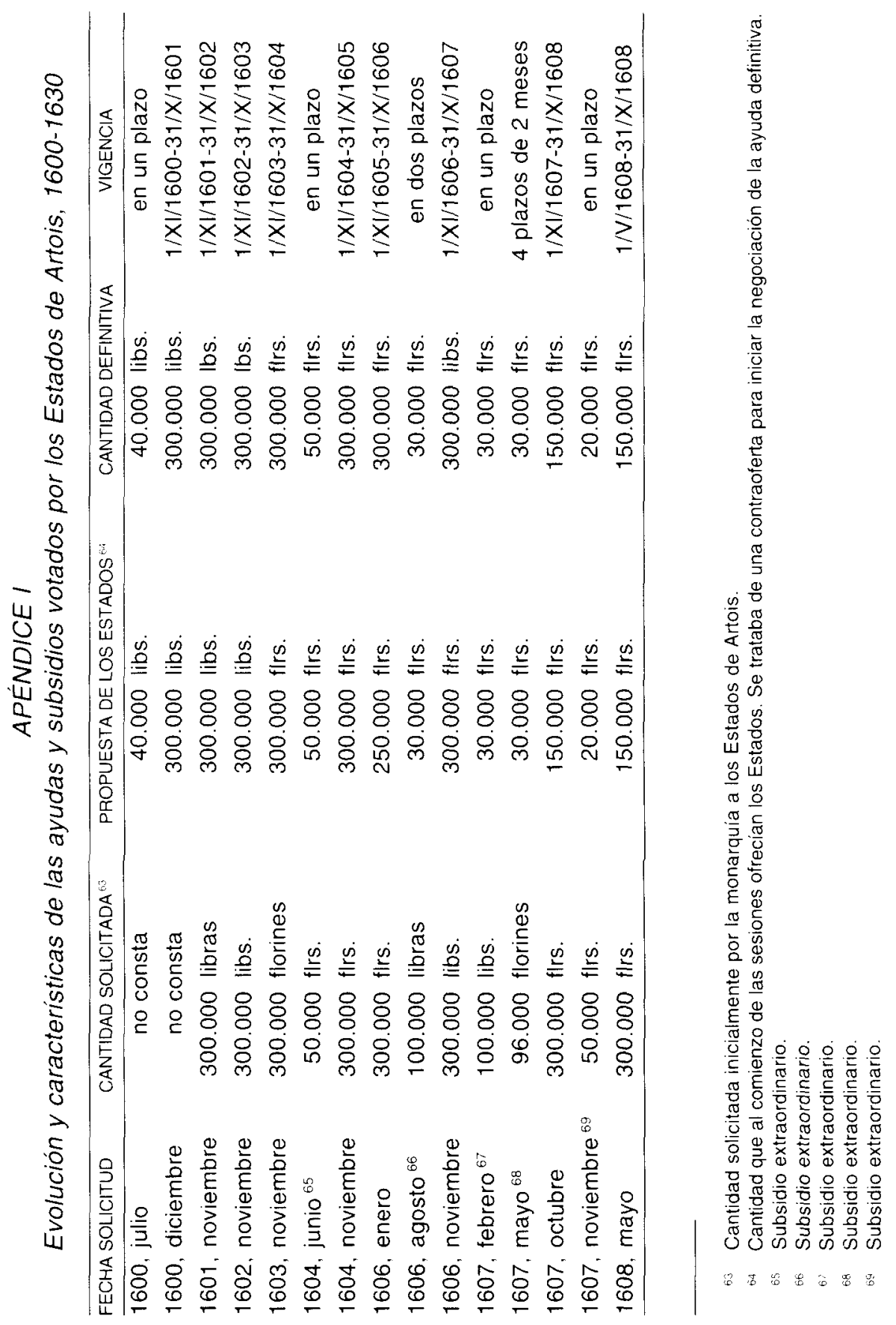




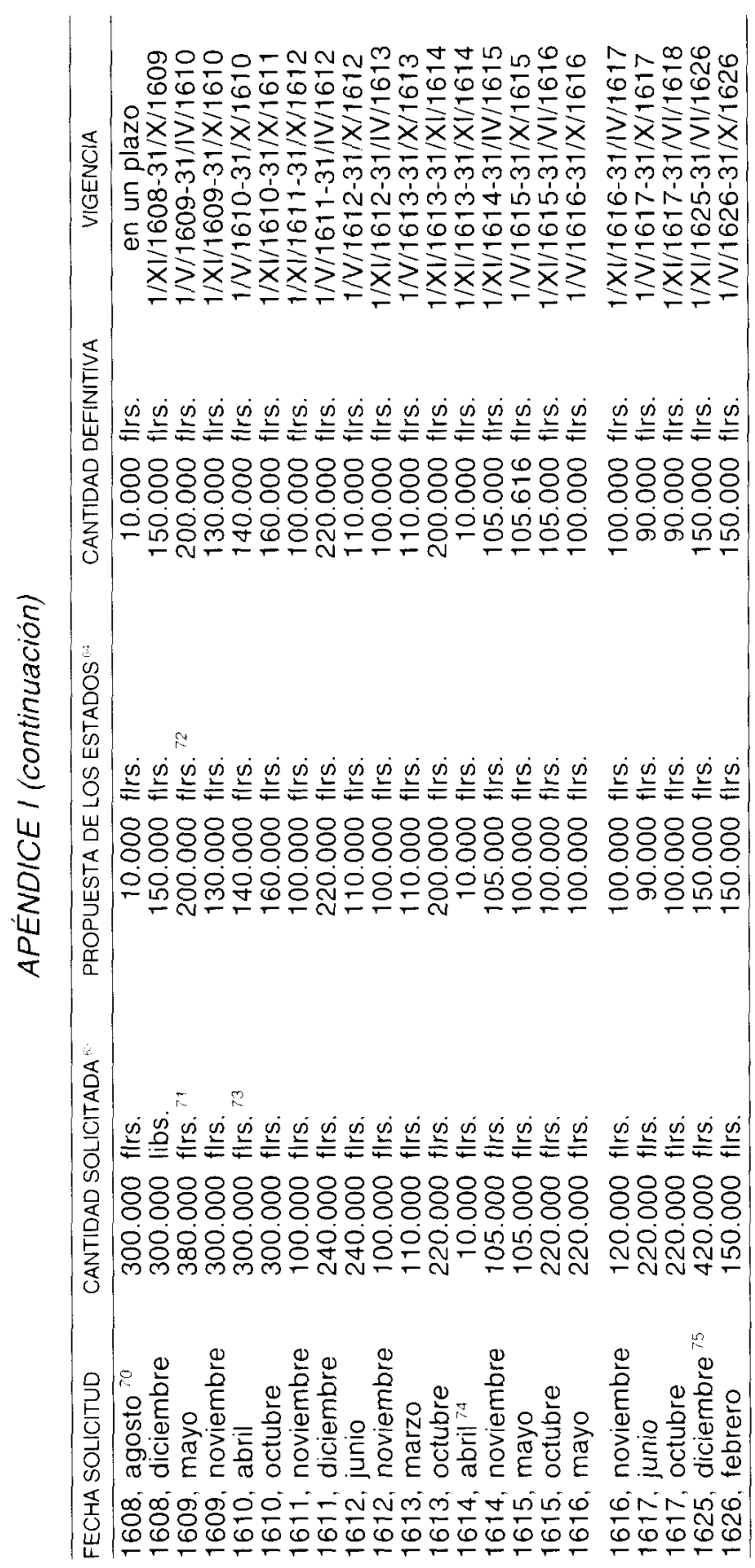



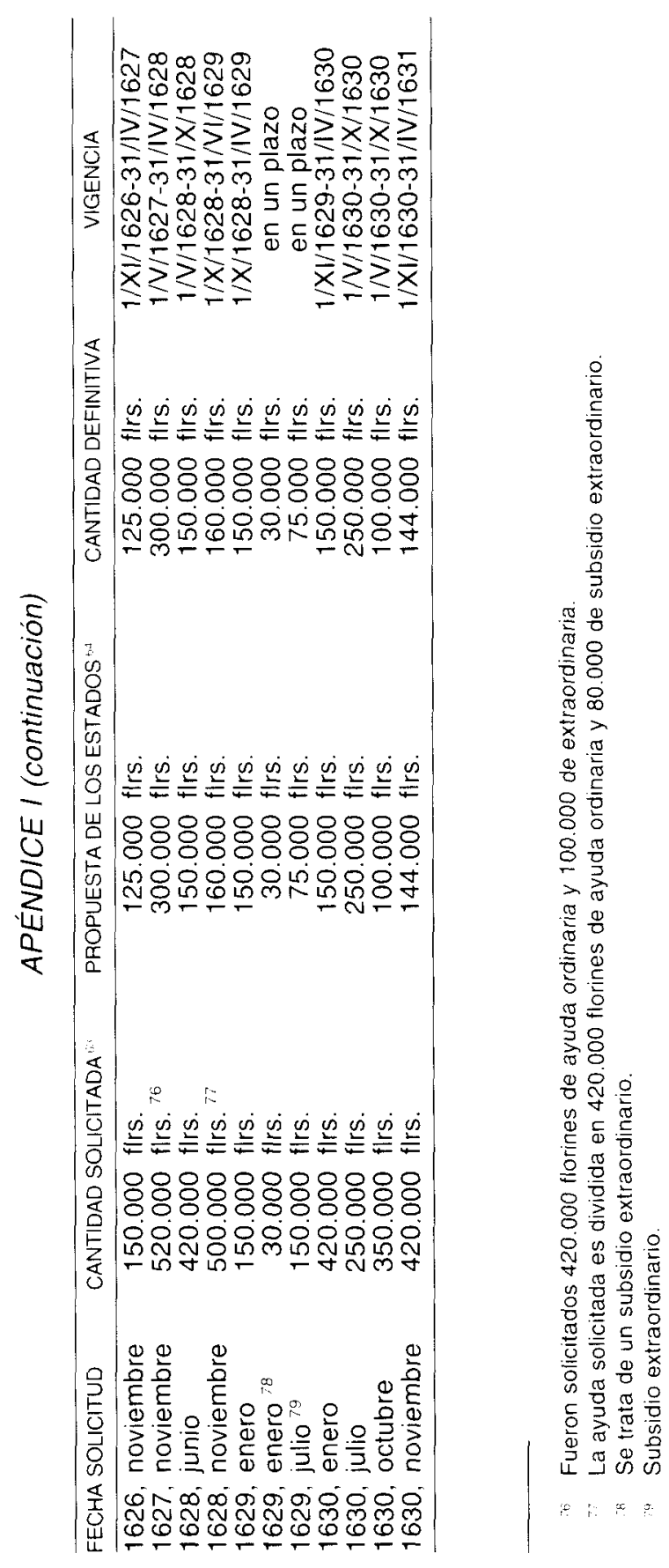


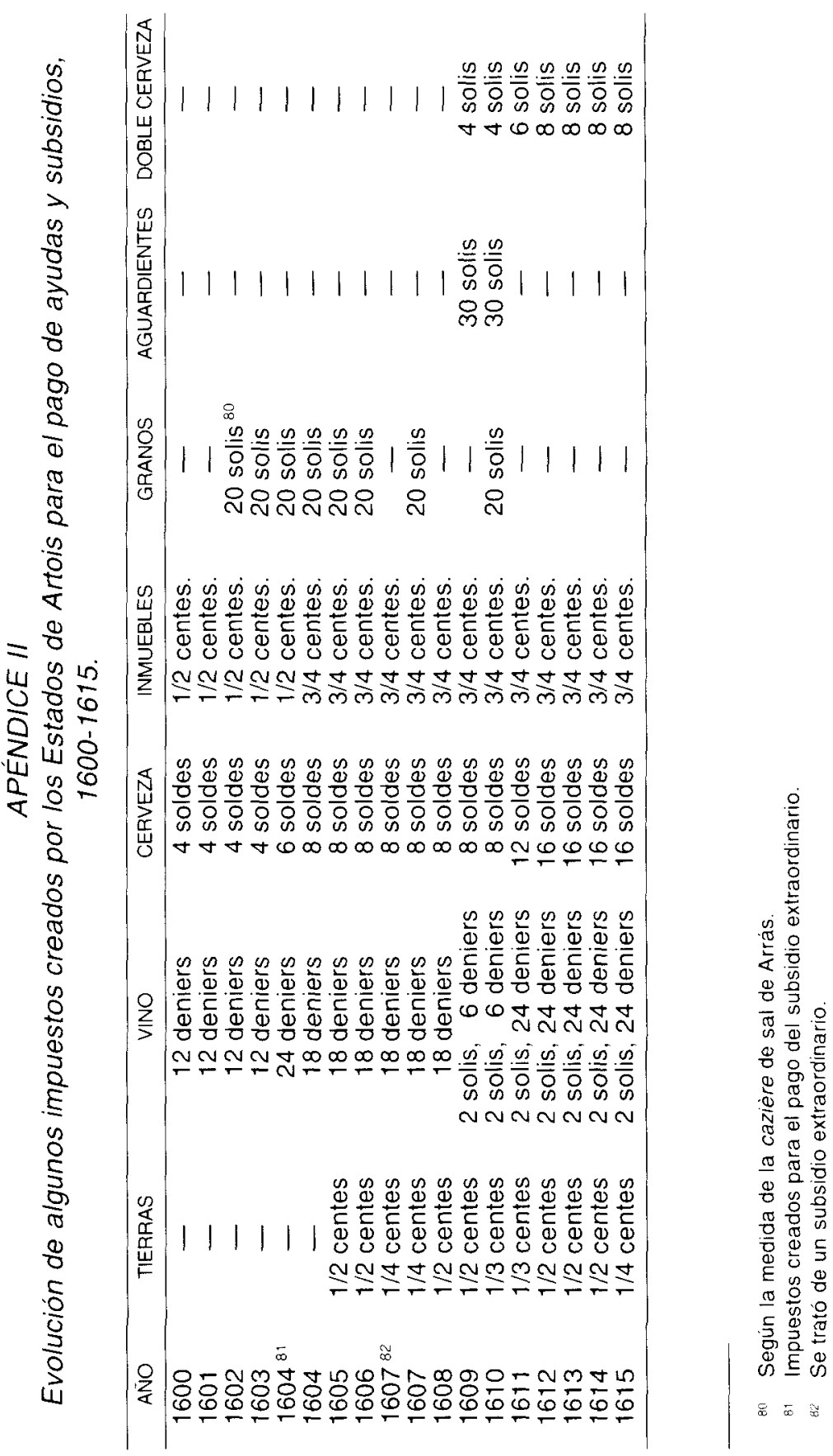

